\title{
Physicians' attitude towards Cancer and Cancer Patients in Jose R Reyes Memorial Medical Center
}

\author{
Deepak Sundar Shrestha ${ }^{1,2,3}$, Sajani Manandhar ${ }^{2}$, Rajendra Rijal', Corazon A \\ Ngelangel $^{4}$
}

${ }^{1}$ Department of Internal Medicine, Jose R. Reyes Memorial Medical Center, Manila, Philippines. ${ }^{2}$ Richa Bajimaya Memorial Foundation, Nepal. ${ }^{3}$ Department of Internal Medicine, People's Dental College and Hospital (PDCH), Kathmandu, Nepal. ${ }^{4}$ Section of Medical Oncology, Jose R. Reyes Memorial Medical Center, Manila, Philippines.

\begin{abstract}
Introduction: This study evaluates the attitude of physicians regarding cancer the disease and patients with cancer, which may influence their management allowing for recommendations of appropriate interventions. Methods: This is a cross-sectional study, which interviewed 251 physicians of Jose R Reyes Memorial Medical Center regarding their attitudes on cancer and cancer patients. The study also explored and identified factors associated with such attitudes. The validated modified Cancer Attitude Scale of Haley et al $(1968,1977)$ was used. Ordinal (proportional odds) regression via Stata was used to examine the association between independent and dependent variables. A score of 1 to 5 was given from strongly agree to strongly disagree for all 21 negatively affirmed questions and a score of 1 to 5 was given from strongly disagree to strongly agree for the 11 positively affirmed questions. The cut off levels to say positive or negative attitude was set as a median score of above 3 for each question representing positive attitude and score of below 3 representing negative attitude. Results: In general the overall attitude of physicians working in Jose R Reyes Memorial Medical Center towards cancer and cancer patients is positive. However the physicians are skeptical of the patient's inner resource to cope with cancer. Expertise, years of practice (of more than 25 years), having experience with cancer patients, being active in religion, Filipino nationality and protecting oneself from carcinogens showed to be associated with positive attitude. Conclusion: The factors that affect physicians' attitude towards cancer and cancer patients should be further explored with a larger and more representative population of physicians for a wider view of attitudes across age groups, clinical experience, religion, medical specialty among others; so that appropriate interventions may be devised to determine ways that can positively impact their perception. Hence, improving patient management.
\end{abstract}

Keywords: Physicians' attitude- cancer- cancer patients- perception

Asian Pac J Cancer Care, 5 (4), 307-314

Submission Date: 11/24/2020Ａcceptance Date: 12/31/2020

\section{Introduction}

Cancer is a leading cause of death worldwide, accounting for 7.6 million deaths (around 13\% of all deaths) in 2008. The low- and middle-income countries have been most affected as about $70 \%$ of all cancer deaths in 2008 occurred in these regions. Cancer is a global issue with a global burden. It is estimated that deaths from cancer worldwide will continue rising, with an estimated 13.1 million deaths in 2030 [1].

Cancer has been described throughout the human

history. Edwin Smith Papyrus says about the disease, "There is no treatment." [2]. Hippocrates (460 BC - 370 $\mathrm{BC}$ ), referred cancer with carcinos (crab or crayfish) [3]. This name comes from the appearance of the cut surface of a solid malignant tumor [4]. Celsus (ca. 25 BC - 50 AD) translated carcinos into the Latin cancer. Galen $\left(2^{\text {nd }}\right.$ century $\mathrm{AD})$ called benign tumours oncos, Greek for swelling, reserving Hippocrates' carcinos for malignant tumours. He later added the suffix -oma, Greek for swelling, giving

Corresponding Author:

Dr. Deepak Sundar Shrestha

${ }^{1}$ Department of Internal Medicine, People's Dental College and Hospital (PDCH), Kathmandu, Nepal. ${ }^{2}$ Richa Bajimaya Memorial Foundation, Nepal.

Emails: deepak@richafoundation.org.np,dpakshrestha@gmail.com 
the name carcinoma.

With the development in medical field, there seems to have been a shift of focus in viewing and dealing with cancer. The focus of cancer seems to have shifted more towards the curative aspects of cancer and wanting on the psychosocial aspects of care.

Further with the development of specialization and super specialization, the practice of many doctors has become more and more focusly narrowed. This may have led to more in depth knowledge in a particular subject matter but on the other hand this may have also created a disparity and disinterest to patients and conditions not belonging to this focusly narrowed particular field of specialization. Moreover, physicians themselves being social beings may be affected by many socio-cultural beliefs which may cause differences in their attitudes towards cancer patients and cancer.

Emphasis is made on how important a role any physician plays in determining the overall wellbeing of a patient. The attitude of a physician towards the patient and the disease condition may very well be reflected on his/ her management which may determine the holistic state of the patient.

A study conducted by Blanchard et al, in the year 1981, entitled "Attitudes toward Cancer I: The Impact of a Comprehensive Oncology Course on Second-Year Medical Students", focused on the change in medical students' attitudes toward cancer and related issues when the factual knowledge concerning the contemporary treatment of the cancer patient was increased [5].

The study conducted by Cohen et al conducted in the year 1982, entitled "Attitudes Towards Cancer II: A Comparative Analysis of Cancer Patients, Medical Students, Medical Residents, Physicians and Cancer Educators", determined how cancer patients, medical students, medical residents, physicians not oriented oncologically, and cancer educators differ with respect to attitudes towards cancer [6].

Grassi et al (2000) conducted a study entitled 'Physicians' attitudes to and problems with truth-telling to cancer patients", considering that disclosure of a diagnosis of cancer to patients is a major problem among physicians in Italy and this differed as per the specialization of the doctors [7].

Another study conducted by Potosky et al (2009), entitled 'Differences Between Primary Care Physicians' and Oncologists' Knowledge, Attitudes and Practices Regarding the Care of Cancer Survivors", also highlighted upon the differences in attitude between oncologists and primary care physicians (PCPs) with regard to their knowledge, attitudes, and practices for follow-up care of breast and colon cancer survivors [8].

This study evaluates the attitudes of physicians towards cancer the disease and the patient with cancer. This study also explores demographic and experiential factors that may be associated with such attitudes.

\section{Materials and Methods}

A cross sectional analytical study was conducted to evaluate the attitude of physicians towards cancer and the cancer patients at one point in time. Further, the demographic and experiential factors associated with the attitude of physicians towards cancer the disease and patients with cancer were evaluated. The study was conducted in a tertiary government hospital in Metro Manila, Philippines - Jose R. Reyes Memorial Medical Center -a referral center for cancer patients in the year 2014-2015. Census Sampling was used with the aim to conduct the study on the entire population $(\mathrm{N})$ of 296 physicians working in the various departments of JRRMMC. All the 109 consultants and 187 residents / fellows-in-training were included in the study except those who were suffering from cancer, undergoing treatment for cancer / had survived cancer, those who were on leave during the study period and those who refused to consent to take part in the study. The physician was given the right to withdraw from the study at any point of time without any questioning or obligations.

\section{Outcome Variables and Measurement}

\section{a. Study Outcome Variables}

The study outcome variable included the dependant variables i.e Attitude of physicians towards cancer and cancer patients. Attitude refers to a positive or negative evaluation of cancer and cancer patients by the physicians. The study also include many independent variables which are the possible factors associated with resultant attitudes. These includes the various demographic and experiential factors and personal behavior for prevention of cancer. Demographic and experiential factors includes Age, sex, expertise, field of specialization, number of years in clinical practice, personal/ family history of cancer, presence of good family ties/ support circle, practice of religion, school attended whether government/ private-non religion/ private-religion, personal experience with cancer patients, professional experience with cancer patients, training on management of cancer patients and nationality Personal behavior for prevention of cancer includes consumption of tobacco and its products, consumption of alcohol, eating healthy diet, and doing regular physical exercise, Hepatitis b vaccination, HPV vaccination, pap smear, mammography, Digital rectal examination and routine self examinations.

\section{b. Data Collection Instrument}

A questionnaire (Appendix A) was used to collect outcome information regarding general characteristics, personal behavior towards prevention of cancer, attitude towards cancer and attitude towards cancer patients.

The following are the parts of the questionnaire:

\section{Part I: General Characteristics}

This section contains questions to assess general characteristics of the physicians, which are gauged as 
possible factors associated with the attitude: age, sex, field of specialization, number of years in clinical practice, personal/ family history of cancer, presence of good family ties/ support circle, practice of religion, school attended whether government/ private-non religion/ private-religion, personal and professional experience of caring for the cancer patients, and training on management of cancer patients and nationality.

Part II: Personal behavior towards prevention of cancer

This section included questions regarding physicians' personal behavior: consumption of tobacco and its products, consumption of alcohol, eating healthy diet, and doing regular physical exercise, hepatitis B vaccination, HPV vaccination, pap smear, mammography, digital rectal examination and routine self examinations.

\section{Part III: Attitude towards cancer}

This section assessed the level of attitude of physicians towards cancer and cancer patients. Modified Cancer Attitude Scale was used [9]. It consists of 32 positively and negatively affirmed statements. Among the 32 questions 11 are positively affirmed and 21 negatively affirmed. The items in the scale are under 4 main factors (second being divided in two further sub-factors). The broad attitude areas that items in the factors relate to are as follows:

Factor I: Attitudes towards the patient's inner resources to cope with serious illness such as cancer.

Factor IIa: Attitudes towards the value of early diagnosis

Factor IIb: Attitudes towards the value of aggressive treatment

Factor III: Attitudes towards personal immortality, preparation for and acceptance of the death.

Factor IV: Attitudes towards cancer patients

Positive and negative attitudes were defined for each question. The positively affirmed attitudes are represented with a $(*)$ sign.

\section{c.Validity \& Reliability of the Attitude Questionnaire}

The attitudes questionnaire (Cancer Attitude Scale) is already validated and used in a published research by Haley et al. Validity/ Reliability tests were done because we added few questions and the study population is different from those of Haley et al in terms of setting. Permission for the use of the original article was obtained from the publisher. However since it is a modified questionnaire, we performed the validity/reliability tests and have mentioned the original source of the questionnaire to be from Haley et al.

\section{Reliability and validity assessment of the questionnaire}

Validity: The questionnaire was distributed to 10 residents/consultants to determine whether the questions were clear and comprehensible (face validity). For the content validity, the same group of residents/consultants who had long experience in working with cancer patients was asked to criticize the content of the questionnaire. Further, they were asked to express their views on whether they considered these 32 questions would adequately evaluate the attitudes of physicians towards cancer and cancer patients or if some additional statements or questions had to be added. The construct validity of the questionnaire was tested using the appropriate statistical technique in order to determine the structure of the questionnaire. For the construct validity evaluation, the 32 questions were used relative to the importance of the 32 statements that assessed the attitude of physician towards cancer and cancer patients.

Reliability: The 10 residents/consultants were asked to answer the questionnaires in order to assess the repeatability. These residents/consultants completed the questionnaire twice. Between the two measurements there was a period of one to four days. The internal consistency as well as the repeatability of each sub-scale derived from the construct validity of the questionnaire was tested using the appropriate statistical test.

\section{Statistical analysis}

Evaluation of the validity and reliability of questionnaires Evaluation of the face and content validity was performed by asking 10 residents/consultants, respectively, to evaluate the clarity/ representativeness of the questions regarding the assessment of attitude of physician towards patients with cancer. Factor analysis was used to evaluate the construct validity of the attitudes' questionnaire. Kaiser-Meyer-Olkin (KMO) and Bartlett sphericity test, which were the initial steps to proceed to Factor analysis were homogenous and this evaluates the degree of correlation among the questions included in the questionnaire.

Statistically significant results of the sphericity test indicate that the variance- covariance matrix of the initial questions of the questionnaire were correlated with each other. A KMO with a value of $>0.6$ showed a correlation and therefore, factor analysis is meaningful. Principal component analysis (PCA) was used for assessment of the main factors. The criterion of Jolliffe (eigenvalue $>$ 0.7) was used to determine the number of factors derived from the factor analysis. Varimax was used to improve the explanatory ability of the factors. Each factor that emerged was interpreted based on the questions that had load value $>0.4$.

The internal consistency of the sub-scales for the attitude towards cancer questionnaire was evaluated by calculating the Cronbach Alpha coefficient. This coefficient ranges from 0 - 1. Large Cronbach Alpha values indicate a high consistency of the questions of which the sub-scale is consisted.

The Intra-class correlation coefficient was used to test for the repeatability of questionnaire, with a $95 \%$ confidence interval, showed that the values were +1 and this showed a high repeatability of the questionnaire.

All statistical analysis was carried out using Stata program, version 12 . 


\section{d. Data Collection}

Data was collected using the validated study questionnaire. The physician-subjects were requested to answer the questionnaire face-to-face with the investigator or were given the option to answer the questionnaire by him/herself, after a brief introduction and instructions given by the investigator.

The time duration for the physician-subject to return the questionnaire was given. The investigator then collected the filled out questionnaires at the agreed upon time. The follow-up of filled-up questionnaire was done 3 times; if after the 3 rd attempt, the physician-subject had not answered the questionnaire, the subject was not included in the study. Identification of respondent was coded and kept confidential.

\section{Data Analysis}

Data entry and data analysis was done using Stata to determine the targeted descriptive and inferential statistics. Frequency, percentage, mean, standard deviation and ranges of scores for each variable were used to present the general characteristics, knowledge and other major variables of the study. Ordinal (proportional odds) regression via Stata was used - This is now becoming the standard method of analyzing ordinal data (Likert scale attitudinal data) to examine the association between independent and dependent variables. A score of 1 to 5 was given from strongly agree to strongly disagree for all 21 negatively affirmed questions and a score of 1 to 5 was given from strongly disagree to strongly agree for the 11 positively affirmed questions. The cut off levels to say positive or negative attitude was set as a median score of above 3 for each question representing positive attitude and score of below 3 representing negative attitude.

\section{Ethical considerations}

This study was carried out in accordance with the Declaration of Helsinki. This study was subjected to the Jose R Reyes Memorial Medical Center Institutional Review Board and Ethics Committee for approval prior to study commencement.

Informed consent (Appendix B) was taken from the physician-participant. The investigator prior to obtaining the consent explained the terms and conditions included in the consent form. The physician-participant was given the right to withdraw at any time during the study period. Involvement in the study did not entail additional cost to the physician-participant. No monetary incentives were provided. Identity of each physician-participant was coded and kept confidential.

\section{Results}

The questionnaire was divided in 3 categories:

I. demographics,

II. personal behavior towards prevention of cancer, and

III. cancer attitudinal survey which included the:

1) Attitudes toward the patient's inner resources to cope with cancer,

2) Attitudes toward values of early diagnosis,
3) Attitudes toward aggressive treatment,

4) Attitudes toward personal immortality and preparation for and acceptance of death and

5) Attitude towards cancer patient.

Data were entered and recoded using the Excel Spreadsheet while data analysis was done performing STATA version 12.0. Attitudinal survey was measured on the categorical scale and tested using ordinal logistic regression to examine the relationship in between variables. A $p$ value $<0.05$ is considered significant.

A total of 295 questionnaires were distributed to the residents, fellows and consultants (1 physician was not eligible to participate in the study and hence excluded). The total number of respondents who completed the questionnaires was 251 , which resulted to an $84.79 \%$ response rate.

The demographic and experiential characteristics of the study population showed that mean age was 35.03 (25 years to 64 years) and mean years of practice was 6.94 (3.5 months to 38 years). The study population were mainly Filipinos $(87.25 \%)$, young adults, with clinical practice, residents-in-training $(72.51 \%)$, knew someone with cancer $(64.52 \%)$, had relatives with cancer/ family history of cancer, and have cared for cancer patients.

Regarding the physician's personal behavior towards prevention of cancer. Many stay away from carcinogens, had recent physical/ oral/ dental check-up, usually eat fruits and vegetables. However, some still smoked cigarettes, and many drank 1-2 glass alcohol at least once a month, exercise less, half practice self-exam. Though required to have Hep B vaccination as a health care provider, only 91\% had this vaccine; HPV vaccine is recommended given at teen years, but few had this vaccine; Pap smear is recommended for sexually active women and few had this screen test. Being a young population at mean age of 35 years, few have undergone Mammography and Digital Rectal Examination (recommended routine screen at 50 years of age).

The attitudes toward the patient's inner resources to cope with cancer are summarized in Table 1. For the physicians, the trend was to agree with the following statements:

- the patient would be psychologically damaged by knowing of his incurable cancer

- the harmful reaction of the patient to the news he has cancer usually overshadows the good of him being told

- any psychological stress on the patient should be avoided

- a patient will not do well unless he has hope of recovery from illness in this life

- the cancer patient may consider himself fortunate to have time to prepare for death rather than to have to face it suddenly

And to disagree with the following statements:

- it is not wise to risk having to deal with a depressed patient by telling him his diagnosis

- the patient generally deteriorates if he knows he has cancer 
Table 1. Factor I, Attitudes Toward the Patient's inner Resources to Cope with Cancer

\begin{tabular}{|c|c|c|c|c|c|c|}
\hline & $\begin{array}{l}\text { Strongly } \\
\text { Agree }\end{array}$ & Agree & Uncertain & Disagree & $\begin{array}{l}\text { Strongly } \\
\text { Disagree }\end{array}$ & Median \\
\hline \multirow{2}{*}{$\begin{array}{l}\text { I think that the patient would be psychologically damaged by knowing of } \\
\text { his incurable cancer }\end{array}$} & 55 & 118 & 27 & 40 & 10 & \multirow[t]{2}{*}{2} \\
\hline & $22 \%$ & $47.20 \%$ & $10.80 \%$ & $16 \%$ & $4 \%$ & \\
\hline \multirow{2}{*}{$\begin{array}{l}\text { I think the harmful reaction of the patient to the news he has cancer } \\
\text { usually overshadows the good of him being told. }\end{array}$} & 21 & 128 & 40 & 50 & 11 & \multirow[t]{2}{*}{2} \\
\hline & $8.40 \%$ & $51.20 \%$ & $16 \%$ & $20 \%$ & $4.40 \%$ & \\
\hline \multirow[t]{2}{*}{ I think any psychological stress on the patient should be avoided. } & 52 & 130 & 22 & 44 & 2 & \multirow[t]{2}{*}{2} \\
\hline & $20.80 \%$ & $52 \%$ & $8.80 \%$ & 17.61 & $0.80 \%$ & \\
\hline \multirow{2}{*}{$\begin{array}{l}\text { I think it is not wise to risk having to deal with a depressed patient by } \\
\text { telling him his diagnosis. }\end{array}$} & 13 & 47 & 51 & 114 & 24 & \multirow[t]{2}{*}{4} \\
\hline & $5.22 \%$ & $18.88 \%$ & $20.48 \%$ & $45.78 \%$ & $9.64 \%$ & \\
\hline \multirow[t]{2}{*}{ I think the patient generally deteriorates if he knows he has cancer. } & 5 & 32 & 69 & 120 & 25 & \multirow[t]{2}{*}{4} \\
\hline & $1.99 \%$ & $12.75 \%$ & $27.49 \%$ & $47.81 \%$ & $9.96 \%$ & \\
\hline \multirow{2}{*}{$\begin{array}{l}\text { I think a patient will not do well unless he has hope of recovery from } \\
\text { illness in this life. * }\end{array}$} & 19 & 98 & 42 & 78 & 13 & \multirow[t]{2}{*}{3} \\
\hline & $7.60 \%$ & $39.20 \%$ & $16.80 \%$ & $31.20 \%$ & $5.20 \%$ & \\
\hline \multirow[t]{2}{*}{ I think knowledge of dreaded prognosis is detrimental to the patient. } & 10 & 69 & 47 & 107 & 16 & \multirow[t]{2}{*}{3} \\
\hline & $4.02 \%$ & $27.71 \%$ & $18.88 \%$ & $42.97 \%$ & $6.43 \%$ & \\
\hline \multirow{2}{*}{$\begin{array}{l}\text { I think it is better not to use the word cancer when answering a cancer } \\
\text { patient about his condition }\end{array}$} & 9 & 55 & 30 & 132 & 25 & \multirow[t]{2}{*}{4} \\
\hline & $3.59 \%$ & $21.91 \%$ & $11.95 \%$ & $52.59 \%$ & $9.96 \%$ & \\
\hline \multirow{2}{*}{$\begin{array}{l}\text { I think the cancer patient may consider himself fortunate to have time to } \\
\text { prepare for death rather than to have to face it suddenly. }\end{array}$} & 33 & 119 & 62 & 26 & 11 & \multirow[t]{2}{*}{4} \\
\hline & $13.15 \%$ & $47.14 \%$ & $24.70 \%$ & $10.36 \%$ & $4.38 \%$ & \\
\hline \multirow[t]{2}{*}{ I feel dealing directly with a patient's feelings about death is to be avoided } & 5 & 37 & 44 & 132 & 32 & \multirow[t]{2}{*}{4} \\
\hline & $2 \%$ & $14.80 \%$ & $17.60 \%$ & $52.80 \%$ & $12.80 \%$ & \\
\hline
\end{tabular}

*Study-driven positive attitudes

- it is better not to use the word cancer when answering a cancer patient about his condition

- dealing directly with a patient's feelings about death is to be avoided

- knowledge of dreaded prognosis is detrimental to the patient.

The physicians got $7 / 10$ positive attitudes and choosing the following statements, not chosen by the study as positive attitudes:

- the patient would be psychologically damaged by knowing of his incurable cancer

- the harmful reaction of the patient to the news he has cancer usually overshadows the good of him being told
- any psychological stress on the patient should be avoided

The attitude towards values of early diagnosis was summarized in Table 2. The physicians got overall positive attitudes.

The physician's attitudes toward aggressive treatment are summarized on Table 3.

For the physicians, the trend was to agree with the following statements:

- only some patients should be treated aggressively

- therapeutic attempts to control a cancer's progress should continue for as long as the patient can be kept alive

- radical surgery for cancer is rarely indicated in patients over 70 years of age

Table 2. Factor IIA, Attitudes toward Values of early Diagnosis

\begin{tabular}{|c|c|c|c|c|c|c|}
\hline & $\begin{array}{l}\text { Strongly } \\
\text { Agree }\end{array}$ & Agree & Uncertain & Disagree & $\begin{array}{l}\text { Strongly } \\
\text { Disagree }\end{array}$ & Median \\
\hline \multirow{2}{*}{$\begin{array}{l}\text { I think complete history and physical examination is usually necessary in } \\
\text { everyday practice. * }\end{array}$} & 168 & 74 & 2 & 2 & 3 & \multirow[t]{2}{*}{5} \\
\hline & $67.47 \%$ & $29.72 \%$ & $0.80 \%$ & $0.80 \%$ & $1.20 \%$ & \\
\hline \multirow{2}{*}{$\begin{array}{l}\text { I think too often doctors are so busy working with sick people that they } \\
\text { can't be expected to do screening procedures and routine complete } \\
\text { physical examinations on all who walk into their offices. }\end{array}$} & 15 & 87 & 25 & 94 & 30 & \multirow[t]{2}{*}{3} \\
\hline & $5.98 \%$ & $34.66 \%$ & $9.96 \%$ & $37.45 \%$ & $11.95 \%$ & \\
\hline \multirow[t]{2}{*}{ I think every person should have a complete physical check up annually. * } & 134 & 100 & 9 & 4 & 3 & \multirow[t]{2}{*}{5} \\
\hline & $53.60 \%$ & $40 \%$ & $3.60 \%$ & $1.60 \%$ & $1.20 \%$ & \\
\hline \multirow{2}{*}{$\begin{array}{l}\text { I think a physician can be so discouraged by the low cure rates of cancer } \\
\text { that he/she will not feel the need to do routine "cancer tests", especially } \\
\text { when he/she is so busy working with the sick people. }\end{array}$} & 0 & 44 & 40 & 116 & 51 & \multirow[t]{2}{*}{4} \\
\hline & 0 & $17.53 \%$ & $15.94 \%$ & $46.22 \%$ & $20.32 \%$ & \\
\hline \multirow{2}{*}{$\begin{array}{l}\text { I think obtaining routine pap smears is more the patient's responsibility } \\
\text { than doctor's. * }\end{array}$} & 34 & 107 & 19 & 82 & 6 & \multirow[t]{2}{*}{4} \\
\hline & $13.71 \%$ & $43.15 \%$ & $7.66 \%$ & $33.06 \%$ & $2.42 \%$ & \\
\hline
\end{tabular}

*Study-driven positive attitudes 
Table 3. Factor IIB, Attitudes toward Aggressive Treatment

\begin{tabular}{|c|c|c|c|c|c|c|}
\hline & $\begin{array}{l}\text { Strongly } \\
\text { Agree }\end{array}$ & Agree & Uncertain & Disagree & $\begin{array}{l}\text { Strongly } \\
\text { Disagree }\end{array}$ & Median \\
\hline \multirow[t]{2}{*}{ I think only some patients should be treated aggressively. * } & 10 & 96 & 35 & 82 & 25 & \multirow[t]{2}{*}{3} \\
\hline & $4.03 \%$ & $38.71 \%$ & $14.11 \%$ & $33.06 \%$ & $10.08 \%$ & \\
\hline \multirow{2}{*}{$\begin{array}{l}\text { I think aggressive treatment of cancer frequently subjects the patient to } \\
\text { illness, pain and expense without much actual benefit to him. }\end{array}$} & 5 & 52 & 55 & 114 & 20 & \multirow[t]{2}{*}{4} \\
\hline & $2.03 \%$ & $21.14 \%$ & $22.36 \%$ & $46.34 \%$ & $8.13 \%$ & \\
\hline \multirow{2}{*}{$\begin{array}{l}\text { I think patients with cancers of low } 5 \text { years survivals (for example } \\
\text { oesophagus, lung, stomach, pancreas) are not improved by aggressive } \\
\text { treatment. }\end{array}$} & 8 & 62 & 61 & 104 & 13 & \multirow[t]{2}{*}{3} \\
\hline & $6.20 \%$ & $25 \%$ & $24.60 \%$ & $41.94 \%$ & $5.24 \%$ & \\
\hline \multirow{2}{*}{$\begin{array}{l}\text { I feel therapeutic attempts to control a cancer's progress should continue } \\
\text { for as long as the patient can be kept alive. }\end{array}$} & 41 & 119 & 49 & 33 & 4 & \multirow[t]{2}{*}{2} \\
\hline & $16.67 \%$ & $48.37 \%$ & $19.92 \%$ & $13.41 \%$ & $1.63 \%$ & \\
\hline \multirow{2}{*}{$\begin{array}{l}\text { I think radical surgery for cancer is rarely indicated in patients over } 70 \\
\text { years of age. * }\end{array}$} & 22 & 119 & 51 & 44 & 12 & \multirow[t]{2}{*}{4} \\
\hline & $8.87 \%$ & $47.98 \%$ & $20.56 \%$ & $17.74 \%$ & $4.84 \%$ & \\
\hline
\end{tabular}

*Study-driven positive attitudes

And to disagree with the following statements:

- aggressive treatment of cancer frequently subjects the patient to illness, pain and expense without much actual benefit to him

- patients with cancers of low 5 years survivals (for example oesophagus, lung, stomach, pancreas) are not improved by aggressive treatment

The physicians got $4 / 5$ positive attitudes and choosing the following statement, not chosen by the study as positive attitude:

- therapeutic attempts to control a cancer's progress should continue for as long as the patient can be kept alive

Table 4 summarizes the physicians' attitudes toward personal immortality and preparation for and acceptance of death. For the physicians, the trend was to agree with the following statements:
- to be realistic, a man has to accept he cannot exist after death

- a person's immortality consists in lingering on in some way through material goods, example, reputation, and offspring

- by detachment from the things of this world a person can have a more real and effective relationship with others and a readiness for death

- a man can be happily reconciled to belief in his own non-existence after death

- there is a possibility of a beautiful death for the cancer patient

- for those patients who are terminal and have not realized it should be told so that they can prepare

- a person should live out his life without concerning himself that death will come

- the dying patient has to be kept happy since he has nothing to look forward to

Table 4. Factor III, Attitudes toward Personal Immortality and Preparation for and Acceptance of Death

\begin{tabular}{|c|c|c|c|c|c|c|}
\hline & $\begin{array}{l}\text { Strongly } \\
\text { Agree }\end{array}$ & Agree & Uncertain & Disagree & $\begin{array}{l}\text { Strongly } \\
\text { Disagree }\end{array}$ & Median \\
\hline \multirow{2}{*}{$\begin{array}{l}\text { I think to be realistic; a man has to accept he cannot exist after } \\
\text { death. }\end{array}$} & 30 & 88 & 52 & 60 & 18 & 3 \\
\hline & $12.10 \%$ & $35.48 \%$ & $20.87 \%$ & $24.19 \%$ & $7.26 \%$ & \\
\hline \multirow{2}{*}{$\begin{array}{l}\text { I think a person's immortality consists in lingering on in some } \\
\text { way through material goods, example, reputation, and offspring. }\end{array}$} & 18 & 111 & 68 & 35 & 15 & 2 \\
\hline & $7.29 \%$ & $44.94 \%$ & $27.53 \%$ & $14.17 \%$ & $6.07 \%$ & \\
\hline \multirow{2}{*}{$\begin{array}{l}\text { I think by detachment from the things of this world a person can } \\
\text { have a more real and effective relationship with others and a } \\
\text { readiness for death. * }\end{array}$} & 39 & 131 & 45 & 25 & 7 & 4 \\
\hline & $15.79 \%$ & $53.04 \%$ & $18.22 \%$ & $10.12 \%$ & $2.83 \%$ & \\
\hline \multirow{2}{*}{$\begin{array}{l}\text { I think a man can be happily reconciled to belief in his own } \\
\text { non-existence after death. }\end{array}$} & 19 & 95 & 86 & 36 & 11 & 3 \\
\hline & $7.69 \%$ & $38.46 \%$ & $34.82 \%$ & $14.57 \%$ & $4.45 \%$ & \\
\hline \multirow{2}{*}{$\begin{array}{l}\text { I think there is a possibility of a beautiful death for the cancer } \\
\text { patient.* }\end{array}$} & 61 & 133 & 36 & 8 & 10 & 4 \\
\hline & $24.60 \%$ & $53.63 \%$ & $14.52 \%$ & $3.23 \%$ & $4.03 \%$ & \\
\hline \multirow{2}{*}{$\begin{array}{l}\text { I think that for those patients who are terminal and have not } \\
\text { realized it should be told so that they can prepare* }\end{array}$} & 66 & 151 & 19 & 8 & 2 & 4 \\
\hline & $26.83 \%$ & $61.83 \%$ & $7.72 \%$ & $3.25 \%$ & $0.81 \%$ & \\
\hline \multirow{2}{*}{$\begin{array}{l}\text { I think a person should live out his life without concerning } \\
\text { himself that death will come. }\end{array}$} & 42 & 92 & 34 & 62 & 14 & 2 \\
\hline & $17.21 \%$ & $37.70 \%$ & $13.93 \%$ & $25.41 \%$ & $5.74 \%$ & \\
\hline \multirow{2}{*}{$\begin{array}{l}\text { I think the dying patient has to be kept happy since he has } \\
\text { nothing to look forward to. }\end{array}$} & 46 & 112 & 37 & 40 & 11 & 2 \\
\hline & $18.70 \%$ & $45.53 \%$ & $15.04 \%$ & $16.26 \%$ & $4.47 \%$ & \\
\hline
\end{tabular}

*Source-Literature-driven positive attitudes 
Table 5. Factor IV, Attitude towards Cancer Patient

\begin{tabular}{|c|c|c|c|c|c|c|}
\hline & $\begin{array}{l}\text { Strongly } \\
\text { Agree }\end{array}$ & Agree & Uncertain & Disagree & $\begin{array}{l}\text { Strongly } \\
\text { Disagree }\end{array}$ & Median \\
\hline \multirow[t]{2}{*}{ I feel sorry for the cancer patients* } & 37 & 103 & 42 & 52 & 12 & 4 \\
\hline & $15.04 \%$ & $41.87 \%$ & $17.07 \%$ & $21.14 \%$ & $4.88 \%$ & \\
\hline \multirow[t]{2}{*}{ I feel no matter what I will do the patient will die soon } & 13 & 51 & 45 & 115 & 20 & 4 \\
\hline & $5.33 \%$ & $20.90 \%$ & $18.44 \%$ & $47.13 \%$ & $8.20 \%$ & \\
\hline \multirow[t]{2}{*}{ I feel cancer patients are burden to their family } & 4 & 30 & 29 & 118 & 65 & 4 \\
\hline & $1.63 \%$ & $12.20 \%$ & $11.79 \%$ & $47.97 \%$ & $26.42 \%$ & \\
\hline \multirow[t]{2}{*}{ I feel cancer patients are burden to the health system } & 3 & 24 & 16 & 112 & 91 & 4 \\
\hline & $1.22 \%$ & $9.76 \%$ & $6.50 \%$ & $45.53 \%$ & $36.99 \%$ & \\
\hline
\end{tabular}

*Study-driven positive attitudes

The physicians got $4 / 8$ positive attitudes and choosing the following statements, not chosen by the sourceliterature as negative attitudes:

- to be realistic, a man has to accept he cannot exist after death

- a person's immortality consists in lingering on in some way through material goods, example, reputation, and offspring

- a person should live out his life without concerning himself that death will come

- the dying patient has to be kept happy since he has nothing to look forward to

Table 5 shows the physicians' attitude towards a cancer patient. For the physicians, the trend was to agree with the following statements:

- I feel sorry for the cancer patients

And to disagree with the following statements:

- I feel no matter what I will do the patient will die soon

- I feel cancer patients are burden to their family

- I feel cancer patients are burden to the health system

The physicians got $4 / 4$ positive attitudes.

The physicians gave $4 / 4$ positive attitude towards cancer patient, $5 / 5$ positive attitudes toward values of early diagnosis, $4 / 5$ positive attitudes toward aggressive treatment, $7 / 10$ positive attitudes toward the patient's inner resources to cope with cancer, and $4 / 8$ positive attitudes toward personal immortality and preparation for and acceptance of death. All in all, the physicians gave a predominantly (24/32) positive attitudes towards cancer and the cancer patient.

Table 6 (Suppl 1): Multivariate analysis looking at the association between the physicians' demographics and experiential factors with the attitudes towards cancer It showed expertise (among residents), years of practice ( $>25$ years), with experience among cancer patients, being active in religion, Filipino nationality and protecting oneself from carcinogens showed to be significantly associated with positive attitudes towards cancer.

\section{Discussion}

The analysis to study the attitude of the physicians working in Jose R Reyes Memorial Medical Center towards cancer the disease and cancer patient suggested that the majority of physicians have an overall positive attitude to cancer and cancer patients. It is good to know that the physicians of JRRMMC have passing scores in their attitudes towards the cancer patient and toward values of early diagnosis, as well as towards aggressive treatment. Expertise (among residents), years of practice ( $>25$ years), with experience among cancer patients, and protecting oneself from carcinogens showed to be significantly associated with positive attitudes towards cancer.

Among the various factors under study it was noteworthy to acknowledge that many sensitive factors, which would be considered to have a big impact on physician's attitude such as having someone close with cancer, practice of religion, specialty, schooling failed to show any statistical significant association with the physician's attitude. It leads us to think that attaining a status of being a physician and handling sensitive condition such as cancer builds the physicians to be more objective and true to their practice as a caregiver, where they don't let their own personal or emotional experiences change their attitude towards dealing with their patients.

It is also in attitudes toward the patient's inner resources to cope with cancer, that the physicians defer, particularly the statements - a) the patient would be psychologically damaged by knowing of his incurable cancer, b) the harmful reaction of the patient to the news he has cancer usually overshadows the good of him being told, c) any psychological stress on the patient should be avoided. This would reflect the training stage wherein the subjects are in, with mostly residents-in-training without yet much experience in patients' ability to cope with cancer. In the multivariate analysis, the more experience the better the attitudes, perhaps duly gained over time. Grassi et al (2000), dealt with physicians' attitudes to and problems with truth telling to cancer patients. There was hesitancy of the physicians to disclose the condition to their patients [7].

Therapeutic attempts to control a cancer's progress continued for as long as the patient can be kept alive was also a preference among the study physicians different 
from study-driven chosen positive attitude. Cohen et al (1982) experience appeared to influence attitudes toward aggressive treatment. Oncologists were the only group who felt as strongly as patients about the value of aggressive treatment and differed significantly from the other professional groups. The context of this study was 'value of aggressive treatment' in curable cancers but not on the context of 'as long as the patient can be kept alive' in all situations even in terminal cancer scenarios [6].

\section{Limitations of the Study}

The study was only looking at the attitude of JRRMMC physicians to cancer the disease and patients with cancer, and hence the study could not be generalized to the larger population of the physicians beyond that within JRRMMC. Majority of respondents were residents with lesser participation from the fellow and the consultants. Hence the main influence of the study was due to the resident population.

In conclusions, in general the overall attitude of physicians working in Jose R. Reyes Memorial Medical Center towards cancer and cancer patients is positive. However the physicians are skeptical of the patient's inner resource to cope with cancer. In the analysis expertise (among residents), years of practice (of more than 25 years), having experience with cancer patients, being active in religion, Filipino nationality and protecting oneself from carcinogens showed to have significant difference with their positive attitudes towards cancer.

\section{Recommendations}

A similar multi-center study be conducted with a larger and more representative population of physicians for a wider view of attitudes across age groups, clinical experience, religion, medical specialty among others.

\section{Acknowledgements}

This research did not receive any specific grant from funding agencies in the public, commercial, or not-forprofit sectors. The authors declare no conflict of interest.

\section{References}

1. Ferlay J, Soerjomataram I, Dikshit R, Eser S, Mathers C, Rebelo M, Parkin DM, Forman D, Bray F. Cancer incidence and mortality worldwide: Sources, methods and major patterns in GLOBOCAN 2012. International Journal of Cancer. 2014 Oct 09;136(5):E359-E386. https://doi. org/10.1002/ijc. 29210

2. Hajdu SI. A note from history: Landmarks in history of cancer, part 1. Cancer. 2010 Oct 19;117(5):1097-1102. https://doi. org $/ 10.1002 /$ cncr.25553

3. Kennedy B. Book Review. New England Journal of Medicine. 1991;324(2):133-4.

4. Kundu C, Mohapatra P, Preet R, Das D, Satapathy S. Anticancer Drugs Designed by Mother Nature: An Old Lock Needs a New Key. 2014;

5. Blanchard CG, Ruckdeschel JC, Cohen RE, Shaw E, McSharry J, Horton J. Attitudes toward cancer: I. The impact of a comprehensive oncology course on second-year medical students. Cancer. 198106 01;47(11):2756-2762. https:// doi.org/10.1002/1097-0142(19810601)47:11<2756::aidcncr2820471135>3.0.co;2-g

6. Cohen RE, Ruckdeschel JC, Blanchard CG, Rohrbaugh M, Horton J. Attitudes towards cancer. II: A comparative analysis of cancer patients, medical students, medical residents, physicians and cancer educators. Cancer. 198209 15;50(6):1218-1223. https://doi. org/10.1002/1097-0142(19820915)50:6<1218::aidcncr2820500634>3.0.co;2-a

7. Grassi L, Giraldi T, Messina EG, Magnani K, Valle E, Cartei G. Physicians' attitudes to and problems with truth-telling to cancer patients. Supportive Care in Cancer. 2000 01;8(1):4045. https://doi.org/10.1007/s005209900067

8. Potosky AL, Han PKJ, Rowland J, Klabunde CN, Smith T, Aziz N, Earle C, Ayanian JZ, Ganz PA, Stefanek M. Differences Between Primary Care Physicians' and Oncologists' Knowledge, Attitudes and Practices Regarding the Care of Cancer Survivors. Journal of General Internal Medicine. 201107 22;26(12):1403-1410. https://doi. org/10.1007/s11606-011-1808-4

9. Haley H, Huynh H, Paiva R, Juan I. Students' attitudes toward cancer: changes in medical school. Acad Med. 1977;52(6):500-7.

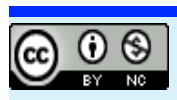

This work is licensed under a Creative Commons AttributionNon Commercial 4.0 International License. 